\title{
El periodismo de proximidad local: los periódicos burgaleses del siglo XIX en la defensa del Patrimonio Histórico Artístico
}

\author{
José María Chomón SeRna \\ Universidad de Burgos \\ jmchomon@ubu.es
}

Recibido: 4 de febrero de 2016

Aceptado: 24 de febrero de 2016

\begin{abstract}
Resumen
Los periodistas de Burgos del siglo XIX desempeñaron un importante protagonismo en la defensa del patrimonio histórico artístico. En un momento en el que la protección de los monumentos no estaba garantizada ni regulada, estos profesionales demostraron con su pluma tener una mentalidad adelantada a la de su tiempo y defendieron la necesidad de mantener, proteger y rehabilitar los grandes y pequeños monumentos. Su intervención y sus denuncias constituyen una demostración de la importancia del periodismo, y en especial del periodismo local.
\end{abstract}

Palabras clave: Monumentos; Periodismo; Compromiso; Denuncia; Protección.

\section{The close local journalism: XIX century newspapers from Burgos defending the historical and artistic heritage}

\begin{abstract}
Burgos journalists, of the XIX century, played an important role in defending the historical heritage of the city. At that moment the monuments protection wasn't regulated. The professionals shown by writing that they were mentality ahead of their time and they defended the need to maintain, protect and restore the big and small monuments. Their intervention and their complaints are a proof of the importance of journalism, and specially, of the local journalism.
\end{abstract}

Keywords: Monuments; Journalism; Commitment; Complaint; Protection

\section{Referencia normalizada}

Chomón Serna, J.M. (2016). El periodismo de proximidad local: los periódicos burgaleses del S. XIX en la defensa del Patrimonio Históricos Artístico. Historia y Comunicación Social. Vol 21, número 1, páginas 97-113.

Sumario: 1. El estado de la cuestión. 2. Metodología y objetivos de la investigación. 3. Los casos concretos: el patrimonio y su defensa por el periodismo burgalés del siglo XIX. 3.1. El expolio de Atapuerca. 3.1.1. El relato de la prensa. 3.1.2. Las medidas de protección y la situación actual. 3.2. La catedral. 3.2.1. El deterioro de las torres. 3.2.2. Retrasos en la ejecución de las obras. 3.2.3. Las vidrieras. 3.2.4. La situación actual del templo. 3.3. Otras referencias monumentales. 3.3.1. El Real Monasterio de las Huelgas. 3.3.2. El arco de San Martín. 3.3.3. El arco de San Esteban. 3.3.4. La Casa del Cordón. 3.3.5. El monasterio de Fredesval. 3.3.6. El monasterio de San Pedro de Cardeña. 3.3.7. La ciudad romana de Clunia. 4. Conclusiones. 5. Referencias bibliográficas. 


\section{El estado de la cuestión}

La reducción de contenidos de proximidad local en las grandes cadenas radiofónicas, el cierre de cabeceras o la progresiva reducción de plantillas reflejan la crisis a la que se enfrentan los medios de comunicación y en especial aquellos con vocación de proximidad local. El ámbito de lo próximo es el ámbito de lo propio, de lo más cercano, aquello con lo que los ciudadanos se sienten más identificados. El territorio, la cultura, las costumbres, el patrimonio histórico y cultural... son elementos de referencia que contribuyen a la formación de una identidad. Son numerosos los autores que destacan la importancia de la información de proximidad como elemento no solo comunicativo sino también identitario, porque determina el entendimiento que el ciudadano posee de la realidad, (Almuiña et al, 2008: 210; Cebrián, 2007: 225; Chaparro 1998: 17: 285-288; Pardo, 2013: 106; Tamarit, 2006: 401).

En este contexto resulta destacable el periodismo de proximidad desempeñado por los periodistas del siglo XIX, que se comprometieron en la defensa de los valores culturales de su entorno, en especial en lo referido a la defensa del Patrimonio Histórico Artístico, en un momento en el que este no gozaba de reconocimiento oficial. Un ejemplo de ello lo constituyen los periodistas burgaleses, que denunciaron ante la opinión pública y las instituciones el abandono y destrucción de los bienes patrimoniales muebles e inmuebles.

El Patrimonio Histórico Artístico, que en la actualidad goza de un reconocimiento universal, constituyó un referente de identidad que hizo que, en los albores del periodismo, se alzasen múltiples voces para poner en evidencia una situación de destrucción y abandono que un grupo de intelectuales y escritores denunciaron, a pesar de que en esos momentos no gozaba de protección jurídica suficiente.

La provincia de Burgos destaca por su ingente Patrimonio Histórico Artístico: Atapuerca, la Catedral, San Pedro Cardeña, el Real Monasterio de las Huelgas, la Cartuja de Miraflores, la Casa del Cordón, los arcos de San Esteban y San Martín, la ciudad romana de Clunia... constituyen bienes patrimoniales especialmente protegidos en la actualidad, que precisaron del apoyo de la prensa local.

El XIX ha sido calificado por algunos autores, en lo relativo a la protección del Patrimonio Histórico Artístico, como el siglo de los despropósitos, ya que se acentuó el esfuerzo por su protección al tiempo que se aceleró su destrucción (Quisosa García María Victoria, 2005: 18). La construcción de un sistema jurídico integral que garantizase su protección fue compleja y lenta. En 1803 se introdujo, por primera vez la noción jurídica de monumento y con la llegada del Estado Liberal y la generalización de la política desamortizadora se instaló una preocupación social y política por el destino de los bienes histórico-artísticos (Martínez Pino, 2012: 11).

El concepto de Patrimonio evolucionó desde un planteamiento particularista, centrado en la propiedad privada y el disfrute individual, hacia una creciente difusión y protección de los monumentos y las obras de arte como ejemplos modélicos de la cultura nacional y símbolos de la identidad colectiva (Llul Peñalva, 180: 2005). 
En el XIX se empezó a tomar conciencia del valor del Patrimonio Histórico Artístico, aunque no fue hasta el XX cuando se produjo una verdadera transformación del sistema de protección.

En el caso de Burgos los periódicos se ocuparon de grandes y pequeños monumentos y los periodistas hicieron suyo el concepto de Patrimonio como bienes pertenecientes a la cultura nacional y local, que simbolizaban la propia identidad del pueblo.

Monasterios, catedrales, puentes, arcos, iglesias, ermitas... son solo ejemplos del interés que los periódicos del XIX mostraron por la protección de todo aquello que tuviera valor patrimonial. Los periodistas denunciaron multitud de situaciones de abandono y destrucción y reclamaron medidas de las autoridades políticas.

\section{Metodología y objetivos de la investigación}

Para elaborar este trabajo se acude a la investigación cuantitativa y se analizan los periódicos del siglo XIX de Burgos que se conservan: El Amigo de la Provincia (1855); El Fomento (1859-1860); Fígaro (1879-1880); La Fidelidad Castellana (1883-1890); Heraldo de Castilla (1880-1881); El Papa Moscas (1878-1920) y Diario de Burgos(1891-actualidad). Mediante la investigación cualitativa se han extraído los contenidos más relevantes relativos al Patrimonio Histórico Artístico. Junto a las noticias seleccionadas sobre esta materia, se ofrece un breve visionado de la situación actual y evolución de esos bienes y el grado de reconocimiento nacional e internacional que han alcanzado. Mediante la investigación cualitativa, se establece también la trascendencia que desde la prensa se otorgó al Patrimonio, cuando su protección era débil y escasa, y el reconocimiento que la evolución social y jurídica le ha dado décadas después.

El objetivo es poder determinar la importancia que el periodismo local de Burgos tuvo en la defensa de los elementos del Patrimonio Histórico Artístico, y si fue una actuación propia de un localismo reductor y provinciano u obedeció al criterio de una prensa visionaria.

\section{Los casos concretos: el patrimonio y su defensa por el periodismo burgalés del siglo XIX}

La provincia de Burgos se configura como uno de los territorios españoles más destacados por su inventario de bienes patrimoniales. En la actualidad, tanto la catedral como los yacimientos arqueológicos de Atapuerca forman parte del Patrimonio Mundial reconocido por la UNESCO. Asimismo, según la base de datos de bienes inmuebles del Ministerio de Cultura, la provincia burgalesa dispone de 200 bienes inmuebles protegidos. Sin embargo, en el siglo XIX esta protección y reconoci- 
miento no existían y fueron los periodistas quienes los defendieron de forma unánime y activa, denunciaron las situaciones de abandono y reclamaron de las instituciones públicas su intervención.

\subsection{El expolio de Atapuerca}

El complejo de cavidades arqueológicas de Atapuerca, referencia internacional para el estudio de la evolución humana, declarado en el año 2000 como Patrimonio Mundial de la UNESCO y objeto de interés de decenas de publicaciones científicas de primer orden, era contemplado en el siglo XIX como un mero objeto de disfrute visual, muy apropiado para la promoción turística, sin que se atisbase lo que encerraba en su interior. A pesar de ello, los intelectuales y periodistas utilizaron las columnas de sus periódicos para ejercer una comprometida defensa de estas grutas y denunciar el expolio al que fueron sometidas.

En 1880 el Ayuntamiento de Valladolid aprobó un proyecto para hacer un jardín romántico mediante la integración de paisajes naturales y elementos artificiales. Se ideó la construcción de un estanque con una cascada y una gruta adornada con estalactitas y estalagmitas. En el mes de abril el director del proyecto se acercó a Burgos para extraer de las cuevas los elementos pétreos. Tras las denuncias de la prensa local, el Gobernador civil, Federico Terrer, requisó la mercancía y prohibió la entrada en la gruta. El Ministerio de Fomento poco después ordenó la entrega del material extraído al Ayuntamiento de Valladolid y la gruta artificial del paseo de Campo Grande, en la capital vallisoletana, exhibe los elementos arrancados en Atapuerca. Algunos no trasladados se quedaron en Burgos (Ortega y Zaparán, 2014: 10).

\subsubsection{El relato de la prensa}

El complejo de cavidades de Atapuerca, situado a unos 15 kilómetros de la capital burgalesa, en 1880 no gozaba de ninguna protección. Algunas de sus grutas albergaban espacios llenos de estalactitas y estalagmitas enormemente atractivos. Nadie sospechaba que guardaba bajo tierra miles de restos fósiles, que se han convertido en esenciales para entender la evolución humana en Europa en los últimos dos millones de años. Sin embargo este expolio no pasó desapercibido para los periodistas burgaleses y fue El Heraldo de Castilla quien dio la voz de alarma:

"el Ayuntamiento de Valladolid está construyendo una cascada en el paseo llamado el Campo Grande, y para adornarla ha comisionado al director de las obras, que es francés, para que viniese á las cuevas de Atapuerca, y tomase de ellas las estalactitas que creyera necesarias para su obra". ${ }^{1}$

El resultado fue la extracción de elementos pétreos en "cantidad bastante para llenar dos wagones". Tras explicar que el gobernador prohibió "llevarse las piedras", se reclamó que no se permitiera su traslado y que sirvieran para adornar los paseos de Burgos. Desde las páginas de El Papa Moscas se calificó el suceso como el "acontecimiento de la semana", y tras girar una vista a su interior denunció que: 
"el destrozo no ha podido ser mayor, las bellezas naturales, que la citada maravilla encierra, han sido destruidas con despiadada mano para adornar un paseo de Valladolid. El atropello que lamentamos, sirva de ejemplo para estimar lo que valen los monumentos que nuestra provincia posee y que tan descuidados solemos tener"2.

La prensa escrita utilizó este suceso para denunciar un problema de mayor dimensión, como era la falta de interés y sensibilidad de las instituciones públicas hacia el Patrimonio:

'Lo mejor es que vengan más franceses, ó ingleses, ó alemanes ó belgas, ú otros marisabidillos por el estilo, y se lleven, no digo la Cueva de Atapuerca, que para nada nos sirve. ¡Dios sea bendito! Sinó la misma torre del Papa-Moscas (en la catedral de Burgos), con reloj, Hércules, Martinillo y todo ${ }^{3}$, porque todo el mundo que gusta entra en la cueva y se llevan los adornos que quieren. ¿Qué es lo que hace la Comisión de Monumentos?"

La extracción de las estalactitas y estalagmitas provocó un cruce de acusaciones y descalificaciones entre una parte de la prensa de Burgos, encabezada por El Papa Moscas, y una parte de la prensa de Valladolid, como El Loro y El Papalaguinda. Se utilizaron descalificaciones como "papagayo, lorito, cotorrón, cotorrilla, loro picotero, ramplón..." en un episodio en el que cada parte defendió la posición de su localidad.

\subsubsection{Las medidas de protección y la situación actual}

Tras el expolio no se adoptaron medidas de protección para el complejo de cavidades. Fue un vecino de Burgos, Ramón Inclán, el que solicitó la concesión "como mina, para explotación de tierras minerales" 5 , con la intención de garantizar su debida protección. La intervención de un ciudadano vinculado al periodismo, Ramón Inclán era fotógrafo y llegó a fundar el periódico Burgos Monumental, implementó unas mínimas medidas de protección del complejo kárstico. Él mismo lo explicó de esta manera:

"Hoy merced a haberla denunciado como mina, para explotación de tierras minerales, se me ha concedido la Cueva, pero mediante el pago de los gastos de expediente, título, contribución, etcétera, como una mina cualquiera. Como complemento le manifiesto que la Cueva ya tiene puerta" 6 .

Las primeras referencias conocidas de la Cueva de Atapuerca aparecen en el S. XV. Sin embargo fue en 1863 cuando Felipe de Ariño y el propio Ramón Inclán publicaron en el periódico El Eco Burgalés el hallazgo de restos humanos en la denominada Cueva Ciega, una de las cavidades del complejo arqueológico. Entonces Felipe de Ariño solicitó la concesión en propiedad durante 60 años de la cueva. Fue el primer intento protector de estas cavidades. (Ortega y Martín, 2012:186-195).

Los periodistas burgaleses defendieron un complejo de cavidades en el que, sin saberlo, se escondían restos fósiles que le han convertido en referencia internacional para el estudio de la evolución humana. Las cuevas de Atapuerca para los periódicos burgaleses del XIX fueron un instrumento para defender lo local, ante lo que entendieron como un expolio de una ciudad vecina y rival. Al mismo tiempo se utilizaron 
como argumento para denunciar la situación de abandono y desprotección de los bienes patrimoniales.

Los yacimientos arqueológicos de la Sierra Atapuerca, de reconocido prestigio internacional, tuvieron que esperar hasta 1991 para ser declarados como Bien de Interés Cultural y hasta el año 2000 para su reconocimiento como Patrimonio de la Humanidad. Según Juan Luis Arsuaga, (1997:16), codirector del proyecto científico de Atapuerca, este complejo "es más que un conjunto de yacimientos arqueológicos: es la clave de la evolución humana en Europa".

\subsection{La catedral}

La catedral se configura como el elemento patrimonial más destacado de Burgos, no solo por su imponente arquitectura gótica, sino también por los cientos de bienes muebles de gran valor artístico que guarda en su interior. Fue el primer bien patrimonial de la ciudad reconocido como Monumento Nacional. "iQué sorpresa, nuestra catedral declarada monumento nacional, histórico y artístico!", se decía en 1885 desde las páginas de El Papa-Moscas ${ }^{7}$. Antes y después de esta fecha fueron numerosas las denuncias, quejas y reclamaciones que desde los medios impresos se realizaron por el abandono y deterioro del monumento burgalés más emblemático. Resulta significativa la forma en que se alertó sobre el uso de algunas dependencias del templo utilizadas como viviendas de los canónigos:

"Se llama la atención del fabriquero á fin de que amoneste, prevenga y advierta que las ventanas de las habitaciones no se hicieron para colgar sábanas, mantas ni mantillas, como en la actualidad lo hacen, particularmente las que tienen vistas á la calle de la Paloma, y subida á la Iglesia, porque á nadie le gusta mojarse cuando no llueve, como sucede á los que por allí transitan y mucho más por el malísimo efecto que causan, porque ciertas prendas de ropa no deben ponerse á donde el público las vé, y jamás en las ventanas que pertenecen á los templos..."

Los periódicos ejercieron una estrecha labor de vigilancia sobre cualquier intervención en el templo. En 1880 se calificaban algunas de las intervenciones como "deformadoras de la arquitectura,", y se recordaba que, a pesar de que los informes técnicos que determinaron la necesidad de intervenir en la Seo para frenar su deterioro, las actuaciones más urgentes siempre tropezaban con la falta de fondos para financiar las obras:

“Al reconocer nuestra hermosa catedral el arquitecto de la de León, ha manifestado que tan notable edificio necesita algunas urgentes y no pequeñas reparaciones. Es pues preciso hacer un esfuerzo y buscar fondos. El pueblo, que no escasea su dinero para toros, bailes, teatros y otras diversiones más ó menos cultas, ¿no ha de prestar su concurso para una obra escudada con el doble amparo de la religión y del arte? ${ }^{10}$ ".

Las quejas emitidas desde los periódicos burgaleses tuvieron una escasa acogida social y política y las propuestas para que la sociedad civil se implicara en la conservación del templo no tuvieron éxito. La falta de recursos económicos se convirtió en 
una denuncia recurrente. Se llegó a acusar al Gobierno de la nación de prestar más atención a la conservación y construcción de cosos taurinos, que a la conservación de los principales monumentos del país:

"Se ha pedido al señor ministro de Gracia y Justicia una subvención para restaurar el interior de las torres de la catedral. El señor ministro ha contestado que perdonemos por Dios. Si hubiera sido para recomponer la plaza de toros de Madrid ya hubiera habido dinero ${ }^{11}$.

Es conocido que la construcción de la catedral de Burgos se dedicó a la Virgen y que una de las tres principales puertas de acceso al templo es la denominada como "Santa María la Mayor", patrona de la ciudad. Además, en su interior son numerosos los bienes muebles dedicados a esta figura. En 1880 se propuso un proyecto de restauración de la imagen sacra de plata de Santa María la Mayor, que el obispo de Acuña mandó construir en 1460. La intervención, que nunca llegó a ejecutarse, pretendía modificar su forma y estructura mediante un sistema de presión y martillazos en la zona de la cabeza:

"se ha propuesto, vergüenza da el decirlo, meter la cabeza de la imagen sagrada en un torno con el objeto de figurar la cara más ovalada a fuerza de presión y dar unos martillazos a las cejas con el fin de hacer bajar los párpados y que la mirada se dirija al público desde la altura donde la Virgen se coloca, porque dicen los...(no nos atrevemos á calificarlos) que tiene la Señora una vista muy altiva...Llévese á cabo la restauración en buena hora, pero de una manera juiciosa, por personas competentes, y no se confíen estas joyas de arte sino á quien los estima y puede apreciar..."

\subsubsection{El deterioro de las torres}

Uno de los acontecimientos más graves para la Seo se produjo en agosto de 1887 cuando en el transcurso de una fuerte tormenta:

“...un rayo chocó en el pináculo ó remate de la aguja derecha, se llevó buena parte de las piedras con que la airosa flecha termina; piedras que cayeron en las calles y casas inmediatas y que hicieron comprender á los vecinos que alguna de las aéreas torres corrían peligro. Desde el puente de Santamaría se nota la desviación del remate de la aguja derecha. El rayo rompió la macolla del vértice de la torre derecha, y descendiendo por la arista norte, desunió varias piedras del norte y oriente, rompió algunas y lanzó otras hasta dar en la torre de la izquierda rompiendo un tabique de una ventana. Otro rayo destrozó en dos sitios la cornisa de adorno del Crucero". ${ }^{13}$

Ante estos sucesos, desde los medios impresos se volvió a recordar el estado de abandono del principal monumento de la ciudad y se exigieron soluciones inmediatas, entre ellas la instalación de pararrayos que evitaran sucesos similares; y la realización de obras de restauración y reparación. Estos son algunos ejemplos de la insistencia que desde de los periódicos se hizo en 1887, 1888, 1890 o 1892:

"Y los pararrayos para la catedral ¿Cuándo se ponen? ¿O es que estamos dando lugar á que vuelvan las tormentas, con ellas las descargas eléctricas. ${ }^{14}$ 
"Ya se avecinan las tempestades con su terrible acompañamiento de tronadas, relámpagos, rayos y centellas, y la torre de la catedral, resentida desde hace once meses se encuentra en el mismo estado..."15

"Se van á colocar pararrayos en la catedral de Moñonedo. Sin duda los de Moñonedo lo hacen para darnos envidia..."16

"Ha terminado la colocación de dos pararrayos en la catedral de nuestra ciudad. Uno ha sido puesto en la torre, en sustitución del antiguo, y el otro en la parte del tejado que cubre el altar mayor. Los trabajos de instalación han sido efectuados por el maestro Herrero D. Tomás Arraiz. El Cabildo parece que ha quedado muy satisfecho... Y yo también lo estaría si los colocaran pronto en esta catedral mía. Porque se me olvidada decir á ustedes que esta colocación tan deseada ha sido en la vecina Vitoria y no en Burgos..."17

\subsubsection{Retrasos en la ejecución de las obras}

Las agujas de la catedral, junto al cimborrio, constituyen la parte arquitectónica más delicada y llamativa del templo burgalés. En los siglos XVII, XVIII y XIX, fueron constantes las actuaciones, sustituciones de piezas, anclajes y cinturas de hierro para mantenerlas en pie. Los destrozos por los rayos agudizaron su deterioro (Navascues Palacio, 1995: 41) y se propuso desmontar en su totalidad la aguja dañada y sustituirla por otra nueva ${ }^{18}$, aunque este proyecto nunca se ejecutó.

Fue necesaria la instalación en 1888 de un andamiaje especial para acometer la reparación de los daños ${ }^{19}$. Años más tarde las obras seguían sin acometerse y la situación de las agujas empeoraba, hasta el punto de que desde los periódicos se alertaba de daños irreparables:

"una vez más en camino de destrucción, pues una de sus torres, denunciada hace algunos años, amenaza con su desplome no sólo de destruirse á si propia, sino concluir con su lindísimo encaje de piedra que se conoce con el nombre del crucero"20.

“Qué hay de las obras proyectadas en la catedral? ¿Qué de los pararrayos? Pues nada ó poco menos. Que la catedral se irá quebrantando poco á poco, que los rayos seguirán cayendo y... que estamos en España. En donde joyas del arte como las iglesias de Sevilla, de Toledo, de León y de Burgos, serán conocidas por nuestros descendientes por... fotografía" 21 .

Hasta 1893 no se instalaron los pararrayos reclamados desde los periódicos ${ }^{22}$, mientras que las obras de reparación y mantenimiento "no han adelantado un paso y lo provisional está en camino de convertirse, como siempre, en definitivo", (Salgado, 1987: 70), y todo ello por "falta de fondos, porque el ministro echó mano de lo consignado en el capítulo de monumentos para extinguir la langosta"23.

La falta de actuaciones que frenaran el deterioro arquitectónico del inmueble provocó graves incidentes, como el desprendimiento en 1898 de una gran piedra "que adorna la fachada de la puerta de Pellejería, que se subdividió en trozos, de los que algunos fueron recogidos por personas que en aquella hora iban al templo"24. Un siglo después se produjo un suceso similar. En 1994 se desprendió del pedestal de la 
torre norte la estatua de San Lorenzo, del siglo XVII y de 300 kilos de peso. Al igual que en 1898 no se registraron desgracias personales. Unos años después, en 2009, se desprendió una de las campanas de la torre sur.

Si en el siglo XIX los desprendimientos de partes arquitectónicas del templo provocaron una mayor concienciación y la activación de las intervenciones, casi 100 años después se repitieron los acontecimientos. La caída de la estatua de San Lorenzo, que a pesar de quedar muy deteriorada pudo ser restaurada, activó las políticas de conservación del templo. Se redactó un proyecto de restauración integral, que con financiación pública y privada, se encuentra prácticamente finalizado. Lo sucedido en el XIX y repetido un siglo después fue explicado con detalle en 1899 en el periódico El Papa Moscas en un artículo que bien podría haberse escrito a mediados del siglo XX:

"por fin se continuarán las obras de reparación de la catedral. Ha sido necesario el empuje de nuestros activos representantes en el poder, y la eficacia del Sr. Ministro de Fomento. Después se realzará y repasará el primer cuerpo de la torre derecha, para evitar la fealdad que hoy presenta. Y luego... á dormir otros ocho o diez años, hasta que á la Comisión de Bellas Artes, negociado respectivo ó Corporación Monumental se le antoje dedicar otras cuantas pesetillas al asunto. De manera que, siguiendo el camino que hasta la presente, cuando se repare una parte del edificio, las demás partes reparadas... necesitarán de nueva reparación"25.

\subsubsection{Las vidrieras}

La catedral de Burgos no conserva la mayor parte de sus vidrieras originales, que destacaban por su riqueza artística, su rica iconografía y la singularidad de sus vitrales rojos; y ello porque "los vidrios se perdieron casi por completo al volar los franceses el Castillo" en 1813, cuando se retiraron de la ciudad ${ }^{26}$. El impacto de la explosión también causó daños en el cimborrio, aguja norte y capilla de los Condestables. Además, en el siglo XVI el Cabildo desmontó un buen número de vidrieras y las cambió por otras de luz blanca:

"La catedral de Burgos con sus vidrios sucios y de mal aspecto y peor gusto que hoy cierran los vanos de las luceras, es una rica joya a la que se han sustituido por toscos trozos de cristal algunas de sus piedras preciosas, es un poema descabalado por la pérdida de varios dísticos armoniosos, recompuesto por la grotesca fantasía del juglar vilipendiado"27.

Los periódicos locales activaron iniciativas para la reposición de unas vidrieras de colores, similares a las originales. La Fidelidad Castellana y La Opinión abrieron una suscripción popular "para costear unas vidrieras de colores" ${ }^{28}$ que debían ser de "estilo siglo XV para decorar las seis ventanas del ábside. ${ }^{29}$ En 1898 se colocaron "a modo de prueba" unas vidrieras en el claustro "que darán más luz y mejor aspecto a aquel sitio" 30 , aunque la falta de fondos impidió continuar con el proyecto. 


\subsubsection{La situación actual del templo}

La catedral de Burgos, catalogada como Monumento Nacional en 1885 y Patrimonio de la Humanidad en 1984, es el bien patrimonial de mayor reconocimiento nacional e internacional. Motor de la industria del sector turístico, ha sido objeto de múltiples restauraciones parciales y de dos grandes procesos de restauración integrales, uno a finales del XIX (Karge 1995: 68-70) y otro a finales del XX.

Fue el primer bien patrimonial de Burgos declarado Monumento Nacional, declaración que impulsó las reformas para hacer frente al estado del templo, que presentaba deterioros importantes en los claustros, torres y agujas. Las obras más relevantes de restauración de la catedral y su entorno fueron las realizadas por el arquitecto Vicente Lampérez a partir de 1893. Algunas de estas actuaciones, como fue derribar la trama urbana enlazada a la catedral, fueron aplaudidas en 1895 por la prensa: "no podemos menos que regocijarnos al ver como avanza la idea del aislamiento de nuestro hermoso templo metropolitano, y el consiguiente derribo del Palacio Arzobispal" (Sagredo, 1987: 86). El viejo Palacio Arzobispal adosado a la catedral fue derribado en 1914 (Carrero, 1997: 169-174).

La segunda gran restauración se inició en 1994 con previsión de finalización en 2017. Tras una inversión superior a los 30 millones de euros, se ha actuado en la totalidad del templo. Se trata de la mayor intervención realizada en la Seo con financiación pública y privada.

De todas las vidrieras, tan sólo se ha conservado el gran rosetón del hastial sur del crucero, de finales del siglo XIII o principios del XIV y de la misma época las cuatro rosetas ovales de la fachada principal, compuestas por vidrios medievales recuperados. El proyecto de restauración contempla reposiciones similares a las originales y la recomposición de otras con los elementos que se conservan del corpus vitriarum catedralicio.

\subsection{Otras referencias monumentales}

El patrimonio monumental de Burgos no solo se ciñe a la Catedral y al complejo arqueológico de Atapuerca, que se han convertido en la principal referencia monumental y cultural de la ciudad. Los yacimientos de Atapuerca se han visto enriquecidos con la construcción del Centro de Investigación sobre la Evolución Humana, el Museo de la Evolución Humana y un auditorio, que se han sumado a la oferta cultural de la vieja cabeza de Castilla. Pero además, son otros 200 los bienes inmuebles de una especial relevancia y reconocimiento protegidos en toda la provincia. Es destacable que el compromiso e intervención de los periodistas burgaleses del XIX no solo se ciñera a la catedral y Atapuerca, también se ocuparon de otros bienes inmuebles considerados como menores en importancia.

\subsubsection{El Real Monasterio de las Huelgas}

Este cenobio cisterciense femenino, fundado en 1189 por Alfonso VIII, se encuentra bien conservado y no sufrió en el XIX percances importantes. Los mayores daños 
fueron provocados por las tropas francesas durante la Guerra de la Independencia, que profanaron los sepulcros reales y sustrajeron una buena parte de sus bienes muebles.

Este monasterio, uno de los monumentos de mayor reconocimiento con que cuenta Burgos, no sufrió las consecuencias de la desamortización, por cuanto no afectó a los cenobios de monjas que quedaron bajo la jurisdicción de sus respectivos obispos. El que estuviese habitado fue también determinante para seguir conservando las obras de arte y la buena estructura del edificio.

Sin embargo ello no impidió que los periódicos mostraran una especial sensibilidad hacia este cenobio y las religiosas que lo habitaban y que por ello se exigieran mejoras. Desde El Fomento en 1860 se pidió el arreglo de los caminos de acceso "para los que reclamamos recomposición. Nosotros necesitamos el arreglo de las vías que parten del monasterio" 31 .

Ese mismo año, por primera vez, se exhibió en procesión en el exterior del monasterio una de sus joyas artísticas, el Pendón de las Navas de Tolosa, arrebatado a los musulmanes en la batalla del mismo nombre en 1212 (Pavón, 2011: 45)

Tejido en oro, plata y sedas, con un tamaño de 3,30 x 2 metros tiene una inscripción con referencias a la figura de Alá. Su uso en procesión fue ampliamente difundida por los periódicos:

"fue un día señalado para la población de Burgos, que admiró, por primera vez, después de seiscientos años, fuera de los compases del Real Monasterio de las Huelgas, el magnífico estandarte árabe ganado en la batalla de las Navas por el noble rey castellano Alfonso VIII al Miramamolín Amamenin Mihamed el Anasir “32.

Desde el siglo XIV se celebra en el barrio burgalés de Las Huelgas una fiesta popular y litúrgica que reúne a las autoridades civiles, religiosas y militares para conmemorar la victoria. Pero no fue hasta 1860 cuando comenzó a exhibirse fuera del monasterio el citado estandarte. En la actualidad se exhibe una réplica, para garantizar la conservación del original, sometido en el S. XX a un proceso de restauración.

\subsubsection{El arco de San Martín}

"El Arco mudéjar de San Martín se está hundiendo. Las maderas que cubren la techumbre están podridas, el agua se cuela fácilmente y concluirá tan antiquísima obra por venirse abajo. Échele el Concejo una mirada compasiva, envíe un par de albañiles y detenga, en lo posible, la destrucción"33

Con estas líneas desde las páginas de El Papa Moscas se llamó la atención de este bien patrimonial utilizado, según la costumbre, para dar solemnidad a la entrada de los reyes a la ciudad:

"Si los monarcas resucitasen y vieran las murallas contiguas, se volvían á la tumba desolados. Poco á poco se irán desmoronando, cada vecino que necesite una piedra se la llevará, y los ricos recuerdos que encierran irán á sepultarse al hogar de algún modesto menestral ó al fondo de una carretera" ${ }^{34}$. 
Tras estas denuncias el Ayuntamiento aprobó en 1894 una moción para la ejecución de obras de mantenimiento y reparación ${ }^{35}$ de este bien patrimonial que data del siglo XIII y que fue la puerta de entrada de los reyes de Castilla a la ciudad hasta el siglo XVI. Integrado en la muralla, se conserva en la actualidad como un elemento aislado, ya que la mayor parte de la fortificación se demolió a partir de 1831 (Sagredo, 1996: 26).

\subsubsection{El arco de San Esteban}

El arco de San Esteban fue declarado en 1931 Monumento Nacional y aunque en el siglo XIX no gozó de ningún grado de protección ni reconocimiento, desde los periódicos se exigió su conservación y se denunció su deterioro. Construido en el S. XIV por alarifes moriscos, forma parte de la antigua muralla de Burgos y destaca por su arco de herradura. Se trata de único bien patrimonial de estilo árabe-mudéjar que se conserva:

"El antiguo e histórico Arco de San Esteban, único acaso en la población de arquitectura árabe-mudéjar, se halla en un estado de ruina lastimoso; y no es esto lo peor, sino que además ofrece inminente peligro de dejar aplastado á cualquiera que pase por él; pues á cada momento se están desprendiendo de los arcos céntricos que forman la clave, trozos de ladrillos" 36 .

Otros arcos, puertas y puentes, todos bienes patrimoniales relevantes, han desaparecido en el siglo XIX como consecuencia de su deterioro y ruina o por el avance urbanístico de la ciudad. Entre ellos se puede resaltar el arco de San Pablo, derribado en 1864 para construir el Palacio de la Diputación; el arco de Santa Gadea, el de los Tintes, el del Hierro o la puerta de Margarita, esta última para construir el Palacio de Capitanía.

\subsubsection{La Casa del Cordón}

La Casa del Cordón constituye un notable edificio de finales del S. XV, muy conocido porque en el mismo los reyes Católicos recibieron a Cristóbal Colón (Cuesta, 1998: 55). Hasta 1968 no fue declarado Monumento Histórico Artístico. Corrió peligro en el XIX y fueron los periódicos los que alertaron y denunciaron algunos de los proyectos que, de haberse ejecutado, hubieran supuesto su desaparición.

"El histórico monumento burgalés, la Casa del Cordón, se ha vendido, y en breve, aquella casa que mandaron facer don Pedro Fernández de Velasco y doña Mencía de Mendoza, su mujer, Condes de Haro, será derruida, desapareciendo para siempre los muchos e importantes testigos de tantos hechos relacionados con la historia patria, testimonio perfecto del amor que los gobiernos profesan al arte nacional, permitiendo que la piqueta demoledora acabe con nuestros más apreciables monumentos, gloria de España y envidia del extranjero"37.

La Casa del Cordón ha sido objeto de múltiples iniciativas, desde su fallido intercambio por el Teatro Principa ${ }^{38}$, hasta los acuerdos municipales proponiendo su adquisición por el Estado ${ }^{39} \mathrm{e}$ incluso su posible destino como Capitanía General ${ }^{40}$. El Ayuntamiento llegó en 1891 a elaborar una memoria sobre las obras necesarias para consolidar este inmueble ${ }^{41}$, aunque su restauración integral no se llevó a efecto hasta 
bien avanzado el S XX, para su conversión en sede de Caja de Burgos, hoy adquirida por La Caixa.

\subsubsection{El monasterio de Fredesval}

Del antiguo monasterio de Fredesval, del S XV, pocos son los vestigios que se conservan. Representa uno de los ejemplos más simbólicos del deterioro y pérdida de los bienes patrimoniales. Fue declarado Monumento Nacional en 1931 y en la actualidad lo que queda es de propiedad privada. En la prensa del XIX fueron constantes las denuncias por el deterioro de un inmueble que, aunque no gozaba de protección jurídica que obligara a su conservación, representaba uno los testimonios más importantes de la historia de Castilla:

"lo que resta del antiguo monasterio de Fresdeval, próximo á esta ciudad, con el objeto de aprovechar la piedra para otros usos. Llamamos la atención de la Comisión de Monumentos, que ya entiende en el asunto, para que se oponga a tal devastación, pues si el monumento no es de primer orden, personifica la historia y tradiciones del país y está lleno de enterramientos de venerables varones. Allí se retiró el emperador Carlos I á su abdicación, si bien los facultativos le obligaron á ir a Yuste, y allí se perpetúan muchas tradiciones del país" ${ }^{\prime 42}$.

En 1895 el Ayuntamiento de Burgos aprobó una moción para intentar "salvar lo que aún queda de este rico flerón de la corona de nuestra hermosa ciudad"43. Su deterioro fue consecuencia de su abandono y expolio. Probablemente se pueden encontrar pocos ejemplos de un monasterio cuya titularidad pasara por tantas propiedades diferentes, y sometido a un expolio tan generalizado y consentido. A ello se añade que resultó muy afectado por la Guerra de la Independencia, (Martínez, 1997: 147-150):

“de la esfera religiosa pasó a la administrativa, y de allí maltratado, á la mercantil. Albergó una fábrica de cerveza y otro nuevo dueño se hizo cargo de las ruinas, de tal forma que los sillares han comenzado á desmontarse y á venderse, y cuando los ingenieros de la provincia han necesitado piedra, en ninguna parte la han encontrado más barata ni en mejores condiciones. La culpa de la ruina se debe a la impremeditación de una venta con la cual el Estado en bien poco se lucró"44.

\subsubsection{El monasterio de San Pedro de Cardeña}

Fundado en el año 902 y considerado como lugar cidiano emblemático, tras su abandono en 1836, fue ocupado en 1888 por los Padres Escolapios, que se encargaron de las obras de restauración más urgentes ${ }^{45}$. Su adquisición por la congregación de los Padres de San José de Calasanz ayudó a garantizar su adecuada conservación mediante la ejecución de obras de reparación y consolidación:

“El magnífico e histórico monumento de San Pedro de Cardeña, tumba del Cid Campeador y de su esposa Doña Jimena, que fue además regado con la sangre de 150 mártires y sobre el que había pretensiones de que fuese habilitado para Presidio Correccional, ha pasado á ser propiedad de los Padres de la Compañía de San José de Calasanz, conocidos con el nombre de Paúles, haciendo magníficas obras de reparación y conservación en el edificio, las cuales han comenzado á realizarse"46. 
Los Escolapios lo volvieron a abandonar en 1901 y en 1933 acogió a una comunidad cisterciense que lo habita en la actualidad. Está declarado Bien de Interés Cultural con la categoría de Monumento desde 1931.

\subsubsection{La ciudad romana de Clunia}

La ciudad romana de Clunia -Colonia Clunia Sulpicia- se encuentra situada entre las localidades burgalesas de Coruña del Conde y Peñalba de Castro. Se trató de una de las poblaciones romanas más importantes del norte de Hispania. Esta urbe adquirió su máximo esplendor en los siglos I y II de nuestra era y tras su decadencia y despoblación ha sido sometida hasta épocas recientes a un progresivo saqueo. En 1855, desde las páginas del periódico El Amigo de la Provincia, se destacó la importancia de los restos que aún quedaban, entre ellos una estatua que fue intervenida judicialmente antes de su venta:

La estatua fue hallada por Santiago Lucas en una de sus posesiones en Clunia el 16 de febrero del año anterior y que gracias a los Srs. Juez de Primera Instancia y Alcalde Corregidor de Aranda de Duero, pudo evitarse que saliera de nuestra patria conducida por algún especulador" ${ }^{\text {"47 }}$

Asimismo el periódico literario Fígaro (1879-1880) explicó en el artículo "Las ruinas de Clunia" la situación de expolio generalizado que sufrió este bien monumental y patrimonial:

“...para hallar y estudiar las obras cluniacenses, no hay que llegarse a Clunia, sino pasear por todos los pueblos comarcanos y vecinos que se han apoderado de los sillares romanos para construir las casas; ver los rollos que todos los aldeanos colocan en las plazas y son columnas romanas; y fijar la atención en las repisas de los balcones, que suelen ser cornisamentos de los templos que a poco hemos mencionado. Nuestra imaginación enmudeció al encontrase con una ermita levantada en el décimo de los siglos, cuya decoración se había verificado con restos de la insigne ciudad. Parte del páramo de la ciudad romana se ara hace muchos siglos; se ha perdido el índice de la edificación latina"48.

Su protección quedó garantizada en 1956 tras su declaración como Monumento Nacional. Un equipo interdisciplinar se encarga de la consolidación de algunos de sus elementos, como el teatro y el foro, y realiza excavaciones arqueológicas.

\section{Conclusiones}

El siglo XIX se caracterizó por la ausencia de una regulación jurídica integral de protección del Patrimonio. A pesar de ello los periódicos ejercieron una labor de denuncia constante de los casos de abandono y destrucción de los bienes históricos.

En Burgos el único bien que se declaró en el S. XIX Monumento Nacional fue la catedral, en 1885. Sin embargo, antes y después de esa fecha, la prensa defendió los bienes patrimoniales en un momento en el que no gozaban de la debida protección. 
En este sentido participaron del concepto de Patrimonio como bienes pertenecientes a la cultura nacional y local, que simbolizaban la propia identidad del pueblo.

Los periodistas, que eran personas ilustradas en una sociedad con altos índices de analfabetismo, supieron valorar la importancia de la herencia histórica y artística y ejercieron una labor de vigilancia y defensa de lo propio. Su labor, en momentos en los que eran habituales las condenas a periodistas y periódicos por críticas a los poderes establecidos ${ }^{49}$, ayudó a conservar y mantener una parte del Patrimonio, aunque no evitó la destrucción de algunos elementos de gran valor.

Este papel de defensa de los bienes patrimoniales, refrenda la importancia del periodismo local desde sus orígenes, y constituye un ejemplo de cómo desde los inicios del periodismo los contenidos de proximidad son esenciales para la comunidad y la sociedad a la que pertenecen.

A tenor del reconocimiento y la protección que los monumentos reseñados han tenido con el paso del tiempo, se puede descartar que la actuación de los periodistas y periódicos burgaleses del XIX estuviera guiada por una visión localista, reductora y provinciana. Se puede concluir que los periodistas se enfrentaron a políticos e instituciones en la defensa de lo propio y mantuvieron un criterio crítico y de periodístico visionario.

\section{Referencias bibliográficas}

ALMUIÑA, C. et al, (2008) La relevancia de los medios de comunicación en Castilla y León. Valladolid. Consejo Económico y Social de Castilla y León.

ARSUAGA, J.L. et al, (1997) Atapuerca. Madrid. Editorial Complutense.

CARRERO, E., (1997) "Restauración monumental y opinión pública. Vicente Lampérez en los claustros de la catedral de Burgos" en LOCVS AMCENVS, 3, pp.161-176.

CEBRIÁN, M. (207) Modelos de radio. Desarrollo e innovaciones. Madrid. Fragua.

CUESTA, M., (1998) Cristóbal Colón. Etapas de su biografía y en su obra. Burgos: Caja de Burgos.

CHAPARRO, M., (1998) La radio pública local. Madrid. Fragua.

ORTEGA, A.I., y MARTÍN, M.A., (2012) Cuevas de Atapuerca. Burgos. Diputación de Burgos.

KARGE, H., (1995) La catedral de Burgos y la arquitectura del siglo XIII en Francia y España. Valladolid. Junta de Castilla y León.

LLUL, J., (2005) "Evolución del concepto y de la significación social del patrimonio cultural" en Arte, individuo y sociedad, 2005, vol 17, pp. 175-204

MARTÍNEZ, G., (1997) El Monasterio de Fresdelval, el Castillo de Sotopalacios y la Merindad y Valle del Ubierna. Burgos: Caja de Burgos.

MARTÍNEZ J., (2012) "La gestión del patrimonio histórico artístico en el siglo XIX" en Tejuelo, $N^{o} 12$, pp-10-21 
NAVASCUES, P., (1995) "Arraiz y la restauración de las agujas de la catedral de Burgos"en AARR: revista cuatrimestral de historia de la arquitectura, 1, pp41-48.

ORTEGA A.I., y ZAPARÁN, M., (2014). "Cueva Mayor y los Jardines Románticos: La Isla de Burgos y Campo Grande de Valladolid", en Diario de Atapuerca. Fundación Atapuerca.

PINO, J., (2012) "La Gestión del Patrimonio Histórico Artístico en el S XIX" en Tejuelo. Revista de ANABAD Murcia, pp. 10-21

PARDO, R.S., (2013) "Las Aportaciones de la prensa de proximidad a la formación de las comunidades locales. Veintidós años de Levante de Castellón" en Historia y Comunicación Social. Vol 18, pp-105-114.

PAVÓN, J., (2001) "La batalla que cambió la historia" en Nuestro tiempo, Septiembre 2011, pp-45-52.

QUICOSA, M.V., (2005). Historia de la protección de los bienes culturales muebles. Granada. Editorial de la Universidad de Granada.

SALGADO, A.(1987) Un Siglo DB 1891-1991: La Historia a través de Diario de Burgos Tomo I. Diario de Burgos.

SAGREDO, J., (1996) Guía de los monumentos municipales de Burgos. Burgos. Ayuntamiento de Burgos.

TAMARIT, A.M., (2006) Consideraciones sobre el periodismo local en Castilla y León en Zer, 20, pp-399-409.

\section{Notas}

1 El Papa-Moscas, $\mathrm{n}^{\circ} 336,20-7-1884, \mathrm{pp}-3$

2 El Papa-Moscas, $\mathrm{n}^{\circ}$ 110, 4-4-1880, pp-2

3 El Papa-Moscas, $\mathrm{n}^{\circ} 110,4-4-1880, \mathrm{pp}-1-2$

4 El Papa-Moscas, no 113, 25-4-1880, pp-2

5 El Papa-Moscas $\mathrm{n}^{\circ}$ 683, 25-1-1891, pp-3

6 El Papa-Moscas n 688, 1-3-1891, pp-2-3

7 El Papa-Moscas, $\mathrm{n}^{\circ} 375,19-4-1885, \mathrm{pp}-2$

${ }^{2}$ El Papa-Moscas, $\mathrm{n}^{\circ}$ 279, 17-6-1883, pp-2

9 El Papa-Moscas, no 407, 29-11-1885 pp-2

10 El Papa-Moscas, $\mathrm{n}^{\circ} 336,20-7-1884, \mathrm{pp}-3$

11 El Papa-Moscas, no 357, 14-12-1884, pp-3

12 Heraldo de Castilla, no 29, 7-7-1880, pp-1

13 El Papa-Moscas, no 498. 28-8-1887, pp-1

14 El Papa-Moscas, no 415, 25-12-1887, pp-3

15 El Papa-Moscas, no 538, 3-6-1888, pp-2

16 El Papa-Moscas, no 673,16-11-1890, pp-2 
17 El Papa-Moscas, $\mathrm{n}^{\mathrm{o}}$ 757, 26-6-1892, pp-3

18 Diario de Burgos, núm.11.447, 7-11-1928, pp 1

19 Fidelidad Castellana, $\mathrm{n}^{\circ}$ 1599, 2-8-1888, pp-3

20 El Papa-Moscas, ${ }^{\circ}$ 698, 10-5-1891, pp-1-2

21 El Papa-Moscas, no 761, 24-7-1892, pp- 3

22 El Papa-Moscas, no 822, 24-9-1893, pp-3

23 El Papa-Moscas, no 914, 30-6-1895, pp-2

24 Fidelidad Castellana, $\mathrm{n}^{\circ}$ 1429, 7-1-1888, pp-1

25 El Papa-Moscas, no 1217, 11-6-1899, pp-2

26 Heraldo de Castilla, no 6, 17-4-1880, pp3

27 Heraldo de Castilla, no 3, 7-4-1880, pp1

28 El Papa-Moscas, no 397, 20-9-1885, pp-2

29 Heraldo de Castilla, $\mathrm{n}^{\circ}$ 115, 27-4-1881, pp 1

30 El Papa-Moscas, $\mathrm{n}^{\circ}$ 1165, 12-6-1898, pp-3

31 El Fomento, no 46, 8-9-1860, pp-368

32 El Fomento, no 32, 21-54-1860, pp-225

33 El Papa-Moscas, $\mathrm{n}^{\circ}$ 595, 19-5-1889, pp-3

34 El Papa-Moscas, no 429, 2-5-1886, pp-2

35 Datos tomados del Archivo Municipal de Burgos. En http://archivo.aytoburgos.es/burgos/doc?q=Ar$\mathrm{co}+\mathrm{de}+\mathrm{San}+\mathrm{mart} \% \mathrm{C} 3 \% \mathrm{ADn} \& \mathrm{star}=17$ \& rows $=1 \&$ sort $=$ fecha $\% 20$ asc $\& \mathrm{fq}=$ media\&fv $=* \& \mathrm{fo}=$ and

36 Fidelidad Castellana, $\mathrm{n}^{\circ}$ 1761, 19-2-1889, pp-3

37 El Papa-Moscas, n 263, 25-2-1883, pp-2

38 El Papa-Moscas, $\mathrm{n}^{\mathrm{o}} 270,15-4-1883, \mathrm{pp}-2$

39 El Papa-Moscas, $\mathrm{n}^{\circ}$ 415, 24-1-1886 pp-3

40 El Papa-Moscas, $n^{\circ}$ 141, 31-10-1880, pp-3

${ }^{41}$ Datos tomados del Archivo Municipal de Burgos. En http://archivo.aytoburgos.es/burgos/doc?q=Ca$\mathrm{sa}+\mathrm{del}+\mathrm{Cord} \% \mathrm{C} 3 \% \mathrm{~B} 3 \mathrm{n} \&$ start $=31 \&$ rows $=1 \&$ sort $=\mathrm{fecha} \% 20 \mathrm{asc} \& \mathrm{fq}=$ media $\& \mathrm{fv}=* \& \mathrm{fo}=$ and

42 El Heraldo de Castilla, ${ }^{\circ} 38,7-8-1880, \mathrm{pp}-2$

43 El Papa-Moscas, no 927, 29-9-1895, pp-2

${ }_{44}$ El Heraldo de Castilla, $\mathrm{n}^{\circ}$ 162, 15-10-1881, pp-1

45 Fidelidad Castellana, ${ }^{\circ}$ 1673, 2-11-1888, pp-2

46 El Papa-Moscas, no 551, 26-8-1888, pp-3

47 El Amigo de la Provincia n $^{\circ} 20$ del 14 de febrero de 1855, pp 3

48 Fígaro, número 11 del 11 de mato de 1879, pp-3

49 El Papa-Moscas, no 139, 17-10-1880, pp-1-2 